\title{
Love as a Fictitious Commodity: Gift-for-Sex Barters as Contractual Carriers of Intimacy
}

\author{
Christopher S. Swader • Olga Strelkova - Alena Sutormina • \\ Viktoria Syomina • Volha Vysotskaya $\cdot$ Irene Fedorova
}

Published online: 7 December 2012

(C) Springer Science+Business Media New York 2012

\begin{abstract}
Gift-for-sex (GFS) barters are a niche practice potentially representing the commodification of everyday dating practices. We inquire how GFS exchanges are practiced and understood in contemporary Russia. Second, we situate these in relation to contemporary economic culture. Our project provides answers in two steps based on online content. First, we identify GFS exchange practices within a major dating website. Next, we take the signals exchanged in those dating profiles and display their intersubjective meanings in Russia based on blogs and discussion fora. Our analysis focuses on gender roles and inter-gender conflicts, the use of economic jargon, the link between luxury consumption and sexuality, and understandings of gift-giving and generosity, in order to show how GFS barters, despite being contractual, carry emotional and romantic content. As such, love is under a constant conversion process, through the medium of the contractual gift, into the fictitious commodity form.
\end{abstract}

Keywords Compensated dating - Fictitious commodification · Gift-exchange · Post-socialist transformation · Economic jargon $\cdot$ Sexuality

\section{Introduction}

How does the modern economic culture influence intimate social relationships? Classically oriented scholars have investigated the ways in which capitalism, consumerism, or money are in constant tension with core human sociality. Meanwhile, contemporary economic sociologists have become skeptical of such claims. In two leading critiques, Zelizer (2005), for example, claims to overturn

C. S. Swader $(\bowtie) \cdot$ O. Strelkova $\cdot$ A. Sutormina $\cdot$ V. Syomina $\cdot$ V. Vysotskaya $\cdot$ I. Fedorova Department of Sociology, NRU-Higher School of Economics, Ul. Myasnitskaya 20,

10100 Moscow, Russia

e-mail: cswader@hse.ru 
"hostile worlds" argumentation by revealing the socially layered and complex subjective meanings that individuals assign to their economic activities, while Granovetter (1985) argues similarly by revealing the webs of social relationships that give the economy its life. At their core, such critiques try to unseat classical 'commodification' arguments by revealing the social meanings and networks that underlie economic activity. Yet, these accounts, although they highlight new ways of understanding the social nature of the economy, do not fully negate the analytical value of commodification. ${ }^{1}$

The definition of commodification that we use here is the process by which things may be brought to be interchangeable on a market. In Marx's words, the commodity, in being so, transcends its use value and becomes exchangeable. The commodified table, for example, "not only stands with its feet on the ground, but, in relation to all other commodities" (Marx 2010). When things become interchangeable, they become objectified and stripped of their qualities, as Simmel also notes as a result of money exchange (Simmel 1995; see also Horkheimer and Adorno 2002).

Beyond the inanimate, we are here concerned with human beings and their intimate practices. Most definitions of 'intimacy' are historically bound and normatively laden. An example is Lynn Jamieson's definition of “disclosing intimacy”, which is a form of "being close" that emphasizes knowing and understanding one another, which she distinguishes from both practical "love and care" and from physical intimacy (Jamieson 1988: 1, 19). We intentionally choose a definition that is more broad and less historically rooted, in order to allow us to explore the largest possible range of commodification effects. Hereby, we refer to intimacy as a wide range of practices involving "being close", whether emotionally, physically, or romantically.

When considering the commodification of the intimate instead of the inanimate, several problems emerge. Human beings are not produced, nor are they usually bought, shipped, and sold as completed products. Therefore, Karl Polanyi's notion of "fictitious commodities" is important for understanding how people and their previously existing forms of social relations become converted into labor (2001). Moreover, conversion into a fictitious commodity is an ongoing process, one that necessarily involves uprooting and restructuring, the breakdown of opposing social forms. Yet, although particular aspects of human beings may become fictitious commodities, such as their sexual work, this process does not often apply to the whole person. While the body may undergo conversion into commercial sex, the intellect and emotions may be kept somewhat insulated from this process. Therefore, questions then arise of the boundary and dissonance between those parts of the self being continuously converted into fictitious commodity forms and those parts that are not (see Silver 1994).

Because of the reintroduction of capitalism after the collapse of the USSR, the post-socialist setting is ideal for researching the connection between intimacy and economic culture. Furthermore, Russia is a crucial case. As the largest postcommunist state, as well as that which experienced the most tumultuous bout of "shock therapy" in its economic reforms, it is also the society that experienced the most profound ideological collapse and a simultaneous explosion in luxury consumer culture. Each of these factors makes Russia an important test case for

\footnotetext{
${ }^{1}$ Granovetter's embeddedness and Polanyi's embeddedness are not inherently incompatible.
} 
investigating changing intimate relationships during the economic transformation. Two relevant trends begin our inquiry into the Russian case with the collapse of the Soviet Union. First of all, the public discourse on sexuality was substantially liberalized. In the private sphere, one of great plasticity (Giddens 1992), a "sexual revolution" took place (Kon 1995: 267). Yet at the same time, with the replacement of the planned economy with a market economic system, it is imperative to inquire to which extent fictitious-commodification has come into play. A fundamental reorganization of the practices of work, consumption, leisure, and values has reshaped Russian life in important ways linked to the growing dominance of market economic culture. Hence, the question arises as to which intimate practices we should look at in order to examine the effects of economic cultural change.

On the surface, an investigation of commercial sex work would seem to yield the highest payoff for an 'intimacy as a fictitious commodity' question. Yet its strong normative and theoretical valences make it a less than ideal place to look. It is tricky to question the 'commercial' aspects of prostitution when commercialization is assumed from the outset. Moreover, there are already ample observations of the increase of prostitution in Russia toward the end of and since the collapse of the USSR (e.g., Kon 1995: 223-224). However, another reason to look elsewhere than at commercial sex is the need to differentiate between commercial sex and commodification processes more widely, because while commercial sex may be an extreme case of fictitiouscommodification of intimacy, it scarcely exhausts the range of practices that involve both intimacy and economic exchange. Along these lines, a more interesting and comprehensive indicator for commodification may be the spread of market-oriented thinking within relationships that do not involve monetary payments, those that are not explicitly commercial in form. Such a 'spillover-effect' could indicate the spread of market logic into the everyday social sphere (see Habermas' 'colonization of the lifeworld' concept, 1989). With this in mind, we have decided to investigate the role of commodification within a particular form of dating relationship.

Gift-for-sex (GFS) exchanges, also known as compensated dating, are a fruitful practice upon which to focus in relation to this question. For instance, in Poland the film "Galerianki" (2006, "Mall Girls") refers to a practice whereby high-school girls exchange sex for, for example, a new mobile phone. We have identified similar phenomena in Russia.

We address two research questions. First, how are GFS exchanges practiced and understood in contemporary Russia? Is there evidence for such exchanges? Second, how can these practices be situated in relation to contemporary economic culture? Presuming that a monetary payment might be more efficient for both parties, why would individuals choose a GFS exchange instead?

Considering that no contemporary research has been conducted on GFS exchanges within Russia, where do we begin to look? We argue that, if GFS exchange practices exist at all, we can certainly find traces of them left by Russia's internet-savvy youth. ${ }^{2}$ Therefore, we have chosen to look at a variety of internet material tied to the Russian dating scene.

\footnotetext{
${ }^{2}$ Moscow, for instance, on which this study is mainly based, has an internet penetration of about $95 \%$ for the ages 18-34, and 78 percent for ages 35-44 (Public Opinion Foundation "FOM" 2011).
} 
There are two steps to our empirical analysis: a typology of profiles of a major dating website and an analysis of blogs/fora on key dating concepts. We first created a descriptive typology of the male and female profiles found on a major Russian dating website (Mamba.ru). This typology was built from the users' self-identified dating intentions and the signals they use to communicate with other daters. From this typology, we highlighted those female and male types which signaled that they were interested in some form of GFS exchange. We then took a close look at the signals, concepts, and characteristics possessed by these GFS types and investigated these further on internet blogs and fora. This second analysis step involved examining forum discussions and blog texts specifically for content that revealed intersubjective understandings of key dating concepts and signals.

\section{Background: Family, Sexuality, and Material Support in Russia}

Soviet power appears to have altered the discourse around and structure of GFS barters. Such exchanges are hardly a novelty in Russia, and classical literature often depicted "supported women" (soderzhanki). Such women were mistresses who were economically supported by their, usually married, lovers. Here, material support is built into the literal meaning of their label. While such a practice is distinct from prostitution in that it does not involve a monetary payment and was in fact a long-term mistress relationship, the connotation of the word is explicitly negative, akin to "prostitute". Prostitution itself, aside from mistress relationships, was equally widespread in St. Petersburg in the 1890s as in other European capitals (Kon 1995: 42).

In Soviet years, several trends stripped the 'mistress' concept of its material elements. First the sexual sphere became heavily suppressed and disappeared from public discourse starting in the late 1930s (Mandel 1975: 13). Second, with the postStalinist thaw, the Soviet standard of living rapidly rose throughout the 1960s as near-universal employment was reached. This and professed gender-equality greatly diminished the material need of women to rely upon men for material support. Yet at the same time, partially because of skewed gender ratios because of WW2 deaths, extra-marital affairs and mistresses were widespread (Mandel 1975: 268-269), and this phenomenon continued to rise steadily between 1969 and 1989 (Kon 1995: 174-175). Despite the wide prevalence of mistresses during this period, they were spoken of in a very different way, as "lovers" (liubovnitsi) rather than "supported women", with no material component to the label. Certainly there were mistresses who enjoyed special material privileges because of their relationships (sometimes forced) with powerful party members, but these were not the norm. In these same years, prostitution, of course, indeed existed in Soviet Russia, but it tended to be small scale, not in the open, and unorganized. It was not characterized by brothels, pimps, or call girls (Mandel 1975: 270-271).

In the late 1980s, Soviet economic decline and the later capitalist transformation brought all this into flux. Sex came out of the closet, but in a way that embodied moral panic, 'westernization,' commercialization, and de-romanticization (Kon 1995: 51-52, 267). In the same period, in 1986, a new type of prostitute came into 
the public eye, the "interdevochka", the hard currency prostitute who lived an opulent life thanks to the luxuries she afforded through the foreign cash she obtained for her services (Kon 1995: 223).

The collapse of the Soviet state mostly displaced family policy from state control in the 1990s (Ashwin 2000: 18). Yet, in recent years the conflict between traditional sex-role identities and women's conscious orientations towards professional or creative success was exacerbated due to a cultural re-traditionalization in gender norms. During this period, economic reforms and global crises have caused periods of unemployment and economic crisis in Russia. While women actually were more successful in adapting to the new service sector economy, most of the available vacancies were for manual or low-skilled work: sewing machinists, secretaries, shop assistants, cleaners and other unskilled jobs in the service sector (Rzhanitsyna 1993: 81, as cited by Bridger and Kay 1996: 22). During these hard 1990s, also characterized by the expansion of luxury consumer culture, the terminology for mistress changed again, shifting from "lover" to the woman who seeks a "sponsor".

The continuity between the pre-Soviet "supported woman" and the post-Soviet 'sponsee' is obvious in that both mistress labels highlight the role of material support. However, while "supported woman" embodied a strong negative connotation, "sponsee" does not. In addition, the "sponsor" label actually applies to the man, while the woman is someone who seeks or has a sponsor. In this respect, she is unlabeled. There are indeed other terms that are applied to some women in this category, such as a "pussycat" (kisya), but these labels apply to a gaudy, pretentious style rather than the fact that she receives material support for her company. Soviet power seems to have subverted mistresses' need for material support, and the late and post-Soviet transformation has re-embedded the 'mistress' relationship with material expectations.

\section{Commercial Sex and Transactional Sex}

As noted above, political and economic liberalization, as well as the growth of consumerism, have made prostitution more organized and widespread in Russia since the USSR's collapse. While a commercial/non-commercial dichotomy is often used to evaluate relationships (Sanders 2008), there is great variety within commercial sex work. Research has demonstrated the fluidity of emotions attached to this economic exchange. For instance, "the girlfriend experience" is a form of exchange, which, for the male client, mimics conventional relationships (Sanders 2008). These relationships also embody "courtship rituals", whereby men purchase gifts and entertainment for their commercial sex worker, and these relationships involve a fuller degree of expressed intimacy on the woman's side as well, in terms of conversation, kissing, and caressing which move beyond traditional prostitution boundaries (Sanders 2008: 406). Yet for the sex worker, this remains a working relationship, and her 'performance' emotionally and romantically is a form of emotional labor, and thereby these exchanges are far from mutual or on equal grounds of power (Egan 2003). Despite the gifts she receives on the side, for her this is a form of 'work' for monetary payment. 
This boundary between gift and payment form is critical for subjective understanding of the relationship and for power dynamics between partners. Yet it is characteristically ignored and undifferentiated within the literature. For instance, a well-known example of a 'commodified relationship' is the Japanese 'Enjo Kosai.' The phenomenon is translated as "assisted dating" (McCoy 2004) and describes teenage girls offering intimate services to middle-aged men (Ueno 2003) for a material compensation. Most often, the form of exchange is a monetary payment, so properly speaking, Enjo Kosai is a form of prostitution.

Yet many approaches, such as that of "transactional" sex, do not specify either what is being exchanged or the differentiation in labels assigned to those exchanges. For instance, transactional sex is "exchange of money or gifts for sexual favors" (Chatterji et al. 2004: 1; as cited by Béné and Merten 2008: 881-882). This definition differentiates neither between cash versus material forms of exchange, nor between the payment and the gift form; it conflates these two dimensions. Even where surveys may ask what is precisely transferred, for instance, money, food, or clothing for sex, the analysis conflates these as "money or gift" transfers (Luke 2003, 2006; Moore et al. 2007). In other words, research rarely inquires into the symbolic meanings assigned by participants to the exchanged goods and to the transaction. A monetary gift implies very different power dynamics (in terms of reciprocation) from a monetary payment. Because these terms are more loose, the literature on "Enjo Kosai", "transactional sex", and "assisted dating", is not neatly comparable to our explicit interest in GFS barters.

Nonetheless, there are two portrayals of women in transactional sex research which could also apply to GFS exchanges more specifically (Béné and Merten 2008: 882). First, such women may be seen as victims of structural and cultural forces, whereby the analytical focus is on coercion, economic constraints, peer pressure, and male domination and violence (Barker and Rich 1992; Longfield et al. 2002; cited by Béné and Merten 2008: 882; Kaufman and Stavrou 2004). In the second approach, women are seen as agents who rationally choose and negotiate their own sexual behaviors. Such women highly value their sexuality and try to maximize their ability to profit from it (Silberschmidt and Rasch 2001; cited by Béné and Merten 2008: 882). It is recognized that the reality usually lies between these two extremes (Béné and Merten 2008: 882), with agency and structure in interplay. The main interests for women in participating in such schemes can be categorized as economic survival, enhancing longer-term life chances, and increasing status among peers (Moore et al. 2007: 46).

In the same way that commercial sex work involves a wide range of services (to include the emotional and romantic) that may simulate the non-commercial, everyday intimate relationships involve a wide variety of practices that simulate the commercial (while maintaining elements distinct from it). The GFS barter is one of these. Our accounts of GFS exchanges confirm girls' denial of prostitution and point at practices distinct from commercial sex work. An example of GFS barters are African fish-for-sex exchanges, whereby female fish traders exchange sex for fish, which they then sell in markets (Béné and Merten 2008). Yet among other GFS types, such as with younger non-working women, more romantic or luxurious gifts may become symbolic of the woman's worth and the man's interest in her (Moore 
et al. 2007: 45). Furthermore, when the gift form of exchange is used, violations of the barter contract appear to become more acceptable, as young women may postpone reciprocation (Nyanzi et al. 2001; cited by Moore et al. 2007: 46).

\section{Gift, Exchange, and Intimacy Theories}

In this investigation, we argue for the prominence of the gift, as opposed to the monetary payment, form of exchange for making sense of 'transactional sex' data, which can be analyzed through a range of exchange theories.

Barter, or the trading of objects or services, according to Polanyi, does not upset the balance between the social and economic spheres (Polanyi 2001). Barter does not allow exact calculations of value, or therefore, the calculation of profit, because there is no objective means (in contrast with money) to compare the 'value' of, for instance, goats to chickens. Yet barter is still more 'commercial' than is pure giftgiving, because it involves inter-subjective intention to 'trade': the contract.

Gift-giving is different, for although some scholars are eager to point to reciprocal relations from a birds-eye perspective, gift relations retain a 'veil' in their ideal form, which implies that the reciprocity is hidden, and subjectively not always felt. ${ }^{3}$ Gift-giving serves largely as a means of symbolic communication (Ruth et al. 1999). Bourdieu describes this exchange of gifts through cycles of reciprocity (Bourdieu 1998). Yet there is a gap between the subjective intentions and perception of each individual gift-giving event and the objective reciprocal and power relationship embodied in gift-giving. This is what Bourdieu called the dual truth of the gift (Bourdieu 1998). This duality in the gifting process is also described in that social actors "have an interest in "disinterestedness" (1998: 93). These dual, objective and subjective, truths about gift giving, and the veil of ignorance that may separate them, highlights the necessity to consider both sides in analyzing gift exchanges.

Firth introduced the concept of "equivalent return" when examining the cycle of gifting, whereby the underlying logic of compensation rests in not mere reciprocity but in the equal value of the gift to be returned (Firth 1959, 412-13). In contrast, Osteen has argued for the anti-economic character of gifting, pointing out that the notion of reciprocity "kills" the "spontaneous, altruistic" spirit of gifting (Osteen 2002). Similarly Marcel Mauss (2000) focused rather on the "spirit" of the gift that compels reciprocation by possessing the person who receives it and connects him/ her to the giver. By several accounts, gifts and commodities are opposed to one another. For instance, Carrier notes that "gifts are possessions, commodities are merely property" (Carrier 1995: 12; see also Osteen 2002: 233).

Notably, 'commodification through gifts,' the notion that we explore here, does not fit neatly into the above accounts. Helpful is Coleman's (2000: 74) supposition that actors exchange rights of control either over material resources or even over

\footnotetext{
3 It is key to keep in mind the distinction between subjectively felt 'market-logic' as opposed to conceptually assigned market logic. As social scientists, we may claim that every relation is an 'objective' market-like exchange. Yet critical for us is the distinction between such blanket descriptions and the ways that subjects actually interpret and practice their social interactions.
} 
actors' behavior (in the form of a "disjoint authority relation") to an authority that has an interest different from the subordinate's. It is important to note that the transfer or non-transfer of control, and the breadth of such control, is related to the form of exchange. A 'payment' may transfer absolutely a portion of the self to another's temporary authority, whereas a barter, especially a gift-barter, may dilute this transfer.

\section{Methods}

There are two directions to our content-analysis: a typology of profiles of a major dating website and an analysis of blogs/fora on key dating concepts identified by a subset of those profiles. The typology is created in order to figure out who is engaged in gift-for-sex exchanges and which signals they use to communicate. The analysis of blogs and fora is designed to make sense of the language used in these exchanges.

Our first step involved the creation of a descriptive typology of male and female online dating profiles. The typology is based on signals and intentions found on the dating website profiles, highlighting those which indicate a desire for some form of GFS exchange. The signals, means of self-presentation, the concepts males and females use, as well as characteristics possessed by these GFS types are developed further in the next step, the blog/forum analysis. For our typology, we selected Mamba.ru as the dating site for empirical research. It is the second largest dating website in Russia, with over 7 million profiles. Mamba users specify the types of relations they are interested in and the type of partner they seek, write diaries about themselves, upload photographs, describe their job and material situation, and list their values and material possessions. Mamba.ru also facilitates dates to restaurants, clubs, and even holiday trips between users. The analysis focused on male and female profiles from members aged 16-60 living in Moscow. Because of Moscow's high level of economic development and consumer culture, we estimated a higher chance of finding there the GFS types we were interested in. Our types are differentiated through the signals that members used in their profiles to communicate with others. In creating a typology, we assigned our profiles to a few typological categories rather than consider each case a category on its own.

In contrast to the typology stage, which was purely descriptive, our blog-forum analysis was interpretive. We took four 'types of interest' from the typology stage, those profiles engaged in GFS exchange, and analyzed their symbolic content with the help of blogs and fora discussing the same terminology. Blogs and fora were chosen as sources because they provide understandings of and intersubjective meanings assigned to different relationship practices and the terms used to describe them. Livejournal was chosen as the site for our blog analysis as one of the most popular sites for Russian bloggers: it consists of over 2 million blogs. Forum discussions were selected from Cosmo.ru and Elle.ru. Around 25 GFS-relevant concepts were investigated through about 150 blogs and a number of Cosmo and Elle discussion fora. Rather than capturing "who said what", this analysis focuses on what was said and how. 


\section{Typology Results}

In the interest of parsimony, of the 18 dating types we have identified on mamba.ru, we only report on the four that self-identify as engaging in GFS exchange. These include: (1) the male 'love and marriage with benefits' type, (2) the male 'sex for material benefits' type, (3) the female 'offer both love and sex for sponsorship' type, and (4) the female 'look for long-term sponsorship in exchange for sex' type.

Male "Love and Marriage with Benefits" Type

Men of this type search for "serious" long-term relations. It includes men of different ages who wish for a serious relationship, with the possibility of creating a family. They usually search for a younger woman (the age difference is up to about 10 years). The criteria for the girls they search for includes not only appearance (it is sometimes excluded) but also personality attributes. Yet in this type, men also offer material support for women they fall in love with. They often offer their sponsorship to women to complement the romantic relationship. Sometimes they legitimate sponsorship with some link between feelings and support, such as "If there are feelings - then my help, including material support, is an integral part of our relations", or they make some reference to traditional values: "I always live on the principal that a man should always support a proper level of life for his girlfriend, his children, his family". To many, sponsorship is regarded not only as a payment but rather as a form of general, not only material, support: "sponsorshipis not only an exchange of services for money, and help can be expressed in more ways than material support". These profiles use signals such as seeking marriage, willing to be a sponsor, seeking love, and they avoid mentioning sex.

\section{Male "Sex for Material Benefits" Type}

Among the profiles of this type, men look for sex "once or twice" rather than for marriage. In addition, they specify sponsorship or gift exchange, but they do not look for "commercial" sex. The men who search for sex with material benefits may be married or unmarried. They are usually searching for young, pretty, "slender" women for sex, sponsorship, gifts, and may mark their desire for "sex once or twice" as a code for a primarily physical relationship. "I am looking for a really very pretty girl, decent and adequate for long-term friendship, intimacy and... pleasant dates for both of us. For mutual sexual pleasure. Conditions may be discussed. ( $\$ 1000$ for example, for every meeting, but only as a gift and not as a payment for services, do not mix this up with sex for money)". This type tends to avoid signaling its interest in both "commercial sex" and "love".

\section{Female "Offer Both Love and Sex for Sponsorship" Type}

These women are often 26-33 years old and are looking for men of the 30-40 year old age range. They want to find a sponsor, become a mistress, and perhaps marry. They suppose their main assets to be their beauty and intellect. They exclaim their 
specialness, uniqueness which, as other rare "goods", have a high price. Besides great physical appearances, they emphasize that they are smart, and thus appeal to men who want intelligent, strong women. In terms of expectations, women of this type are not merely after money. They want a "good" man as well: "I am looking for a MAN (emphasis in original)". They search for men who are "generous" and who have realized their goals. These women avoid signals such as "commercial sex.'

Female "Look for Long-term Sponsorship in Exchange for Sex" Type

Another female type wants a long-term sponsor in exchange for sex, but does not offer "commercial sex" and does not want to start a family with the sponsor. These girls simply search for a sponsor and do not feel shy about expressing their material needs. They are often 20-30 years old, present themselves as young and beautiful, and say that they search for an older (28-40 years old) prosperous, generous, and self-realized man, who can become their long term lover. They often note that it is not a problem if he is married. They can be characterized as mistresses who want men to give them gifts, to pay for their Mamba.ru "VIP" statuses, to put money on their phones, take them on exotic vacations, buy them I-Phones, or pay for university fees. Some of these are students, and most do not work full time. The diaries of women who belong to this group are rare and short. These females can be divided into two types of self-presentation. The first type is characterized by the want to seem to be pleasant, nice, sociable, good. The second type's members present themselves as capricious, selfish, fastidious, haughty, loving only expensive gifts. In such profiles, there is very little direct mentioning of sex "once or twice", although it may be implied in the written text. These women seldom mention marriage or family foundation.

\section{Content Analysis of Blogs/Fora}

In this section we present integrated blog and forum analysis results. Jointly they indicate inter-subjective understandings about compensated dating related signals and terms. We describe these findings according to four main categories: gender conflict, economic jargon, luxury consumerism and 'buysexuality', generosity and gifts.

\section{Gender Conflict}

Online data reveals that compensated dating is framed within a discourse involving gendered and power-laden relationships, and this discourse is one of tension and conflict. Men are depicted as if they only use women for sex. Women perceive this and portray their behavior as a response, one that makes them more "expensive". One writes, "If he treats me as if I only provide sex, I will treat him like a purse". This indicates a subjective empowerment, whereby men commodify women's bodies and women respond by controlling their own "price". These women also 
repossess words applied to them and infuse them with more empowering (financially) meanings: "If I am going to be bitch, why not an expensive bitch!" This becomes a discourse in which all men are seen as objectifying female sexuality, and some women argue for a universal female response to not "give it up" for free, because "romance without financing is nonsense-men do not value free goods (emphasis added). "Some aspects of this response are opportunistic: "Men treat us like prostitutes anyways ... why not get something out of it"? Such women may move from the exploited to the exploiter, and brag about "squeezing money out of sugar daddies". There are multiple male discourses that harmonize with the above account. Of course, other men lambast the style of "manipulative" sexuality they see in some of the above statements. Most discussions look like an attempt to accuse the opposite gender of consumer-oriented relationships. Males accuse females of commercialism and justify an image of poor but generous sugar daddies ("papiki") who are disappointed in women. Women accuse men of competing with one another in a way that diminishes intimacy and demonstrates status by means of the cost and quantity of women. Compensated dating is closely related to strong cultural ideals of romantic gender relations and what happens when both genders allege that these ideals have been 'gutted' by the other. Materialism seems to find its place in the collapse of romantic ideals: "I will say frankly, sweet romance with passionate young men does not interest me. I prefer long relationships on a MATERIAL basis, or separate meetings on the same basis (emphasis in original)".

\section{Economic Jargon}

Central to our analysis, one looking for linkages between new economic culture and changes in intimate relations, is the infusion of economic jargon into compensated dating relationships. For example, "sponsorship" has a mostly positive connotation and indicates a relationship whereby a monetary gift is given regularly to a woman for her long term sexual and emotional services, often presuming monogamy on her part. This relationship is reminiscent of sponsors of professional athletes, except in this case the "sugar daddy" (papik) provides the material support, often in gift form, for the high quality performance of his sponsee, and with minimal interference into her "private life". She may use this gift to buy a fitness studio membership, upgrade her makeup and wardrobe, or visit the beauty salon. This is alluded to often by many women. "Beauty is expensive", they say, and the male's contribution is to maintain the quality of that beauty, which he enjoys directly and indirectly (in terms of status). Interestingly, an older Russian word for sponsee is "soderzhanka", which literally means "supported woman". The connotation of this term is pejorative, almost an equivalent to "prostitute", but the infusion of "sponsorship" terminology into everyday language is in this sense a linguistic privatization, and one that mystifies, perhaps even empowers, the valence of "supported woman" practices.

In addition, women speak of themselves as "investment projects". One student writes, "I would like to meet a man for a relationship with material support. I search for an investor for my studies". Another woman explains that "a woman is like an investment project: how much you put in determines how high your 'profit' will be" 
(quotations in original). In a similar vein, men are referred to as "start-ups" for young and beautiful girls. Such men provide girls with financial support at a difficult time in exchange for something girls have much of: youth and beauty. The relevance of such language for commodification thought is intriguing: it is a direct incorporation of economic jargon within a process of self-commodification. The agentic and self-empowerment/self-employment ramifications of this should not be underestimated. Yet, this language is also instituted upon the girls by men. In certain blogs, men speak of collecting beautiful girls as they would expensive luxury automobiles. In turn, women reapply this language to describe themselves. One pseudo-commercial sex-worker on Mamba writes on her profile "No test-drive included", meaning that her clients should pay for the first intimate encounter.

The role of economic language should not be underestimated. At a minimum, language reflects aspects of reality embedded in other forms of practice. At the other extreme, language provides the very concepts by which reality is interpreted, understood, and acted upon. In this second sense, language has commodification relevance by definition. This also raises questions of 'performativity,' whereby the economic culture embodies jargon that its incorporated into, and forms, everyday life.

\section{Luxury Consumerism and "Buysexuality"}

In English, "buysexuality" indicates the linkage between sexuality, eroticism, and consumption (see also Illouz 1997). It signifies those who get "turned on" through certain forms of consumption. In Russian blogs, they might be called something more negative, a "classical consumer-bitch", a girl who 'begins to get pleasure from money, in other words she gets off/enjoys luxury life.'

Russian "glamour feminity" (Arutyunyan et al. 2010) indicates a new form of Russian femininity that attaches itself to the glamourous lifestyle of luxury consumption and high-fashion. It is no secret that the fashion industry sells glamour sexuality images alongside its high-fashion products. Also in our GFS exchanges, examples abound of the expectations that some women have of men buying them nice things. Women request particular clothing brands, I-phones, and even automobiles in exchange for intimate relations. One woman warns about her seductive powers, linking them to material needs: "Be careful when chasing beauty, friend! Beauty and love are two sources of suffering, and their wonderful kingdom is not eternal. Your heart is out of your hands. GIVE ME A CAR ALREADY! (emphasis in original)"

The contemporary 'glamour girl' in Russia is also known informally as a "pussy cat" (kisya). According to internet depictions, these are usually girls from a lower educational background who begin to realize their attractiveness very early. Often they may follow in their mother's life course model, which involved growing up in adverse economic conditions. They tend to move as soon as possible away from the regions to the bigger Russian cities of Moscow and St. Petersburg. Developing as "pussy cats, "they learn where and how to find their" targets, "who they call" sugar daddies" (papiki). This type of man is characterized as "collector of beautiful women.' These girls believe that physical satisfaction should be paid for and her 
beauty should be invested in. They prefer earnest collaborations concerning the contractual-like relations ('searching for a sponsor') and attract males by means of an obvious plan. Men report that "it is very simple and clear to be with such girls, that is why males ask for their service and pay them not only for their body but for the honor of a primitive relationship" (emphasis added). Bloggers note that these girls differ from commercial sex-workers by their appearance. Pussy cats are more kept and glamorous. They may have a dog, expensive car, glaring make-up, provocative clothes (in pink and animal patterns). Such girls may attract males by the combination of their "Barbiedoll look and dissolute intentions". While the men brag about their pussy cats, the women behave as real girl-friends in return for money and gifts (trips, jewelry, cars, houses, dogs, clothes, etc.). Bloggers say that these girls are of low class but 'brandish themselves as celebutantes who pretend that they had always had luxury apartments, clothes and lived in five-star rooms'. They are also characterized by strategy of life described in terms of one of the livejournal users: 'These girls who wear pseudo-branded clothes, use cheap unnatural self-tanner and wish to get a rich sugar daddy, and sometimes his son who is better for them.' As for the 'sugar daddies' - these collectors are competitors in a game of 'whose woman is the most expensive?' The women bring them not just company or emotions, but also status. Some male bloggers admire such men for their rich life experience: "they went through water and fire" (or they "went through Crimea, Roma and copper pipes"). Most bloggers agree that, for these men, an expensive girl and her appearance demonstrate such a man's power and leisure.

The sexuality-consumption link does not signify 'commodification for everyday survival.' Rather, it suggests the importance of luxury-consumption, which links contemporary gender roles to the rise of consumer culture.

\section{"Generosity" and Gift-giving}

The above requests for specific items, be it a fur coat, an I-phone, or a car are 'gift requests.' These can be seen as having a particular status within gift-giving theory. The gift often entails a 'double truth' (Bourdieu), its subjectively felt and objectively structured components. In other words, a gift is also a veil-has a "spirit" (Mauss)—which conceals its long term reciprocal functions and embedded power-relations. A gift-request can puncture this veil of assumed altruistic or independent intent and thus appears as a bald-faced exchange. On the other hand, gift-requests can also be a means of signaling to a potential partner the initiation of the symbolic gift process, to include its emotional valences, in which case the specificity of the item may be key or it may be the symbolism of the request itself that is relevant. For instance, "why don't you buy me some red roses?" could be a gift request that connotes a puncturing of the veil, but for the purpose of initiating a relationship related to the symbolism of red roses, romance. Alternatively, "why don't you pick me up a postcard in Paris" can indicate desire to simply initiate the process of gift-exchange, reciprocity. However, "give me a car!" represents an obvious concern with the object and its material properties, and its symbolism that connotes excess and luxury, rather than an interest in the gifting process, the "spirit" of the gift. 
Yet despite that certain gift requests may pierce the 'veil' of the gift, such gifts convey something nonetheless. The act of giving a gift, even a monetary one, by definition conveys the symbolic meaning of "I am not paying you a salary" and "I wish to enter into a reciprocal relationship". Furthermore, particular gifts, such as glamourous or romantic gifts, or in a society where luxurious gifts contain a romantic valence by default, carry additional emotional and romantic energies with them. The act of a man giving gifts also means that he can love. In contrast, a "greedy" man is one who is greedy both with his heart and with his wallet. As one blogger put it: "when a man doesn't give gifts he: 1-doesn't love a woman or 2-adores himself and can't share what he has, 3-is a very greedy guy ... a gift is an equivalent of Love".

To put it in another way, we can ask what the difference is between trading intimacy for monetary payment and trading intimacy for gifts. The difference is that intimacy traded for gifts allows the transfer of something much more than physical sex: mutual emotional intimacy and even 'love' - at least a simulation of it. This feature seems to be confirmed by the fact the GFS exchanges involve fewer boundaries than do payment-for-sex relations. In a society that values finance but stigmatizes commercial sex, a "sponsor" can kiss, exchange sweet nothings with, and romance his "investment project", but not his "whore". The girl taking the gift in exchange for sex avoids not only the "prostitute" stigma, but she also gains the simulation of the 'real' relationship and its emotional exchange. Here the question of commodification comes to a climax. Is this girl more or less commodified than the commercial sex worker? On the one hand, she has fewer boundaries, she "sells" more of herself, more of her emotions, her lips, even sometimes her heart. Some male bloggers note that they would not go to a prostitute mainly because she cannot offer cannot offer them emotional warmth. Can they 'buy' this through gifts? On the other hand, the gift-taker's (as opposed to commercial sex worker) relationship is normalized in the sense that it approximates a 'real' relationship with its emotional exchange; does this simulation mean, then, that she 'sells' less? The same questions can be asked of the sponsor; have material relations more, or less, or differently penetrated his sponsorship relationship than his relationship with commercial sex workers?

Over and over again, women look for men who are "generous" (in gifts and emotions combined, as described above). Men also describe themselves this way to attract women, although some men claim it is unwise to be too generous or that generosity is "showing off". Notably, women never describe themselves as generous; it is not an ideal trait for women. Rather the closest thing we found for women was a negative term describing "getting something for free" (implying using another), "halyava". Important in terms of power dynamics, halyava implies the acceptability and desirability among women of avoiding or violating the barter contract or reciprocal expectations for when she 'owes' sex.

Generosity as a trait in men is also connected with concepts such as "real man", "smart" (luxurious), "attentive", "rich"; "above 40 y.o"., "successful' ('sostoyavshiysya'), and "adequate". Notably, each of these is related to some form of material well-being, while generosity is depicted as 'more' than this alone; material and emotional generosity are depicted as sewn together. In addition to being 
generous with expensive gifts, men may be generous with flowers, sex, feelings, money, time, sweet words, care, and kindness. Interestingly, in this way, female romantic types overlap with 'glamour pussy cats' in discussing the problem of generosity: each of them claims that a man must be generous. Some women complain that such men have "died off". These findings on generosity and giftgiving illustrate at least two main points in relation to the economy-sociality question. First, there is a strong fusion between the economic and the emotional in terms of how women interpret "generosity" to imply both love and material generosity. This points to simultaneously the emotional-romantic power of the gift and at its double truth as a carrier of material power. Second, one important aspect of the gift-giving dynamic seems to be disassembled here; the bald-faced giftrequest punctures the veil of the gift, the subjective ignorance of the double-truth on the part of the gift-exchangers. If John gives Susie a new I-phone as a gift because she requested this in exchange for sex, this has become a gift-barter. Through its contractual nature, a barter is one step closer to a commodified exchange than is a gift exchange. Is this gift's symbolic power weakened as a result?

\section{Discussion}

This analysis has yielded four relevant themes for the discussion on the commodification of intimacy. First, GFS exchange practices are justified in relation to gender roles and gender claims, especially about the exploitative behavior of the opposite gender, whereby men are accused of using women for sex and women are accused of using men for material gain. Here, traditionally "male" and "female" power attributes, whether sexuality or material prowess, are enhanced within a exploitation claims and counter-claims. Second, economic jargon is used rampantly within GFS exchanges, suggesting that economic logic has indeed infiltrated the process, raising also questions about the performativity of economic language upon practices within the intimate sphere. Where the terminology describing a practice implies the commodity form, is this already proof of the practice's conversion into a fictitious commodity? Third, the rise of a 'glamourous' femininity in Russia is reflected in the link between our compensated dating practices and consumption, not of basic food items or for paying rent, but for the purchase of luxury items, such as furs, expensive technology, or even automobiles. Finally, the analysis also reflects directly on gift-giving literature through looking at the language of combined emotional-material "generosity" concerning men, paralleled by women expecting to get things for free (halyava). Furthermore, gift-giving in the GFS exchanges spoken about online is not in its pure form. It may have lost one side of Bourdieu's "double truth", because the subjects exchanging them do not seem to foster many illusions about the pure intentions of the gift. Reciprocity is open and expected, up front, and unveiled. Nonetheless, these gifts still are capable of carrying emotional, even romantic, content.

For clarity, we would like to compare here GFS exchanges with another practice: commercial sex. Some would argue that GFS practices are merely a form of "undercover prostitution". We disagree with this assessment. First, GFS praticioners 
explicitly and vehemently deny that they are involved in commercial sex work and construct the meaning of GFS in ways very different from commercial sex. Second, aside from these subjective differences, this Russian case of compensated dating has many notable differences from commercial sex work. For instance, GFS rarely involves middlemen who control their workers and collect rents for their protection. Notably, GFS practicioners sometimes practice 'less than,' sex, because some girls may refuse sex after receiving gifts. On the other hand, some GFS females practice 'more than' sex, in that commercial sex boundaries in particular prostitution spheres against emotional exchange, kissing, and romance, are removed. GFS relationships may be longer than commercial sex relationships, in that many appear to last beyond several meetings and become longer-term "sponsor" relations. Importantly, GFS practicioners are supposed to maintain the illusion that they have only one sponsor, whereas commercial sex workers openly maintain many clients. Also, in describing themselves online, GFS practicioners tend to give longer and occasionally elaborated narrative accounts about themselves and what they search for in a partner. In contrast, commercial sex workers tend to have very short and direct descriptions of the services they offer. Similarly, commercial sex workers typically have photographs that are sexually explicit, whereas GFS practicioners use photographs that leave more to the imagination. Another important difference is that commercial sex workers have a very low selectivity for partners sought: they seek partners of a huge age range and with unspecified personality characteristics. In contrast, GFS practicioners specify a narrower age range and a greater selectivity in partner personality; this difference could embody the gap between being a 'client' and being a 'partner,' and different marketing demands: quantity to quality. As a result, GFS practices may be safer and more emotionally rewarding than are commercial sex relationships. In addition, the use of the gift format of exchange substantially loosens the expectation of the female's reciprocity in cases where the barter contract is left informal or implicit. In addition, the female 'sponsee' is not available for all 'services' or all clients; she may choose her partner, and her activities with him, based on his respect for her, known through a range of behavior and signs (to include the gift). Thereby, she maintains for herself, through his treatment of her as a unique individual, a sense of self-worth. Yet, in other ways, GFS characteristics overlap with features peculiar to commercial sex workers. In both practices, there are earnest contract-like agreements about the expectations between exchange partners, and these are each also based on mutual benefit.

As a result of this analysis, we are able to reach a preliminary answer to our question of why individuals choose to exchange gifts for sex instead of a monetary payment for sex. Of course, by engaging in a gift-exchange, practicioners are able to avoid the prostitution stigma. Far beyond this, by making a gift-request, especially a nonmonetary one, the female makes to the male her specific wishes, and insodoing, her qualities, known and recognized. She is not completely interchangeable because her requests are unique. Even where she wishes her gift to be in the monetary form, it is her choice rather than his. In addition, the status that the male gains from such a girl may be greater because (1) she is not a "prostitute" and (2) in the case of the nonmonetary gift, he may demonstrate his power and her company within the shop while they are making their purchases together, whereas a monetary exchange removes this additional location of status gain. Beyond these points, however, is that the gift-barter 
allows practicioners to exchange more. Through a monetary payment or a pure barter, one can acquire sex but not authentic mutual care or romance. The gift, as a symbolic medium, allows the interchangeability of that which is not normally interchangeable: love and emotions at a lower degree of simulation. Love and care are not normally exchangeable because they are represented as authentic through persons' instrinsic valuations of one another rather than through instrumental valuations. This same intrinsic valuation is symbolized through the gift-relation's pure form. In this way, compensated daters have written of generosity as a trait applied to both emotions and to material gifts. They represent one another and are thus interchangeable. Yet, properly speaking, these GFS exchanges are contractual, and as such they no longer are 'pure gifts,' subjectively valued as disconnected from exchange. It is more accurate then to term these gift-barters, hybrids that embody both some degree of the emotional-romantic transfers made possible through the gift form and also the contractual nature of the barter. Therefore, GFS barters appear, on the one hand, to open more spheres to conversion to the fictitious commodity form than commercial sex exchanges because they allow the interchangeability of emotions and romance, which are normally more inaccessible within standard commercial sex exchanges, especially for the sex worker him/herself. On the other hand, GFS barters resist complete conversion in that the gift form allows the preservation of the female's unique qualities, by both avoiding the stigma of prostitution and by assigning to the woman's intimate practices a qualitative, not quantitative, value.

There are limits to how much we can generalize on offline activity based on an analysis of internet dating. The content-analysis of online material in this case is a necessary first step in investigating fictitious commodification practices within dating relations in Russia and beyond. Evidence shows that there is indeed a strong footprint of compensated-dating related practices found on the Russian internet, and these appear to be manifested in ways directly relevant to discussions on the shift in Russian economic culture since the collapse of the Soviet Union. At the very minimum, our data suggest that GFS practices in Russia are embedded in the rise of both economicrational (persons as "investments" to be "sponsored") and consumerist (linked to luxury consumption) logics in ways intermingling with changing gender roles ("glamour feminity", Arutyunyan et al. 2010) to affect an aspect of everyday life, dating, to include its emotional and romantic dimensions. The gift-barter may be a means for the conversion of love into the fictitious commodity form.

Acknowledgments Funded by a 'teacher-student' grant from the Academic Fund of the National Research University-Higher School of Economics. Significant research support was provided by Margarita Goldberg and Ekaterina Bounich. The authors are grateful to colleagues Grigory Yudin, Rafael Mrowczynski, Vadim Radaev, Tatiana Karabchuk, Leon Kosals, and Inna Deviatko for their critical remarks and suggestions.

\section{References}

Arutyunyan, M., Zdravomyslova, O., \& Shurygina, I. (2010). Social-pychological problems of children in the modern city. (Социально-психологические проблемы ребенка в современном городе). Conference Paper for "Children and Youth" conference held from 1.03.10 to 4.04.10. Accessed January 4, 2012 online at http://ecsocman.hse.ru/text/33372879/. 
Ashwin, S. (Ed.). (2000). Gender, state and society in Soviet and post-Soviet Russia. London, NY: Routledge.

Barker, G., \& Rich, S. (1992). Influences on adolescent sexuality in Nigeria and Kenya: Findings from recent focus-group discussions. Studies in Family Planning, 23(3), 199-210.

Béné, C., \& Merten, S. (2008). Women and fish-for-sex: Transactional sex, HIV/AIDS and gender in African fisheries. World Development, 36(5), 875-899.

Bourdieu, P. (1998). The economy of symbolic goods. In P. Bourdieu (Ed.), Practical reason: On the theory of action (Chapter 5). Stanford: Stanford University Press.

Bridger, S., \& Kay, R. (1996). Gender and generation in the new Russian labour market. In H. Pilkington (Ed.), Gender, generation and identity in contemporary Russia (pp. 21-39). London, NY: Routledge.

Carrier, J. (1995). Gifts and Commodities: Exchange and Western Capitalism since 1700. London and New York: Routledge.

Chatterji, M., Murray, N., London, D., \& Anglewicz, P. (2004). The factors influencing transactional sex among young men and women in 12 Sub-Saharan African countries. POLICY programme funded by the US Agency for International Development. Washington DC, USA.

Coleman, J. (2000). The foundations of social theory. Cambridge: Belknap Press.

Egan, R. D. (2003). I'll be your fantasy girl, if you'll be my money man: Mapping desire, fantasy and power in two exotic dance clubs. Journal for the Psychoanalysis of Culture and Society, 8(1), 277-296.

Firth, R. (1959). Economics of the New Zealand Maori. Wellington: Government Printer.

Giddens, A. (1992). The transformation of intimacy: Sexuality, love, and eroticism in modern societies. Stanford: Stanford University Press.

Granovetter, M. (1985). Economic action and social structure: The problem of embeddedness. American Journal of Sociology, 91(3), 481-510.

Habermas, J. (1989). The Theory of Communicative Action, Volume 2: Lifeworld and System: A Critique of Functionalist Reason. Boston: Beacon Press.

Horkheimer, M., \& Adorno, T. (2002). Dialectic of enlightenment: Philosophical fragments. (E. Jephcott, Trans.). Stanford: Stanford University Press.

Illouz, E. (1997). Consuming the Romantic Utopia. London: University of California Press.

Jamieson, L. (1988). Intimacy: Personal relationships in modern societies. Cambridge: Polity Press.

Kaufman, C. E., \& Stavrou, S. E. (2004). 'Bus fare please': The economics of sex and gifts among young people in urban South Africa. Culture, Health, \& Sexuality, 6(5), 377-391.

Kon, I. S. (1995). The Sexual Revolution in Russia: From the Age of the Czars to Today. (J. Riordan, Tran.). New York: The Free Press.

Longfield, K., Glick, A., Waithaka, M., \& Berman, J. (2002). Cross-generational relationship in Kenya: Couples' motivations, risks perception and STIS/HIV and condom use. Working Paper No. 52. Washington, DC: Population Services International Research Division.

Luke, N. (2003). Age and economic assymmetries in the sexual relationships of adolescent girls in subSaharan Africa. Studies in Family Planning, 34(2), 67-86.

Luke, N. (2006). Exchange and condom use in informal sexual relationships in urban Kenya. Economic Development and Cultural Change, 54(2), 319-348.

Mandel, W. M. (1975). Soviet Women. Garden City, New York: Anchor Books.

Marx, K. (2010). Capital: A critique of political economy. Moscow: Progress Publishers.

Mauss, M. (2000). The gift. The form and reason for exchange in Archaic societies. (W. D. Hallis, Trans.). New York/London: Norton.

McCoy, A. (2004). Blaming children for their own exploration: The situation in east Asia. ECPAT report on implementation of the agenda for action. Accessed January 24, 2012 on http://www.make-itsafe.net/eng/pdf/Blaming_Children.pdf.

Moore, A. M., Biddlecom, A. E., \& Zulu, E. M. (2007). Prevalence and meanings of exchange of money or gifts for sex in unmarried adolescent sexual relationships in sub-Saharan Africa. African Journal of Reproductive Health, 11(3), 44-61.

Nyanzi, S., Pool, R., \& Kinsman, J. (2001). The negotiation of sexual relationships among school pupils in south western Uganda. AIDS Care 2001, 13(1), 83-98.

Osteen, M. (2002). The question of the gift: Essays across disciplines. New York: Routledge.

Polanyi, K. (2001). The great transformation: The political and economic origins of our time. Boston: Beacon Press. 
Public Opinion Foundation (FOM). (2011). Internet Penetration in Russia. Report from July 18, 2011. Accessed on December 16, 2011 from http://www.ewdn.com/2011/07/18/internet-penetration-inrussia/.

Ruth, J., Otnes, C., \& Brunel, F. (1999). Gift receipt and the reformulation of interpersonal relationships. Journal of Consumer Research, 25(4), 385-402.

Rzhanitsyna, L. (Ed.). (1993). Rabotaiushchie Zhenshchiny v Usloviiakh Perekhoda Rossii $k$ Rynku (Working Women in Russia's Market Transformation). Moscow: Institute of Economics of the Russian Academy of Sciences.

Sanders, T. (2008). Male sexual scripts: Intimacy, sexuality, and pleasure in the purchase of commercial sex. Sociology, 42(3), 400-417.

Silberschmidt, M., \& Rasch, V. (2001) Adolescent girls, illegal abortions and 'sugar daddies' in Dar El Salaam: Vulnerable victim and active social agents. Social Science and Medicine, 52, 1815-1826.

Silver, N. (1994). Prostitution and the mind/body debate. Off Our Backs, 24(11), 22.

Simmel, G. (1995). The philosophy of money. New York: Routledge.

Ueno, C. (2003). Self-determination on sexuality? Commercialization of sex among teenage girls in Japan. Inter-Asia Cultural Studies, 4(2), 317-324.

Zelizer, V. (2005). The purchase of intimacy. Princeton: Princeton University Press. 